\title{
Development and validation of an
} immunohistochemistry assay to assess glucocorticoid receptor expression for clinical trials of mifepristone in breast cancer

\author{
This article was published in the following Dove Press journal: \\ Cancer Management and Research \\ 4 December 2015 \\ Number of times this article has been viewed
}

\author{
Gabrielle M Baker ${ }^{1}$ \\ Tiffany Murphy ${ }^{2}$ \\ Thaddeus Block 3,4 \\ Dat Nguyen ${ }^{3}$ \\ Frank J Lynch ${ }^{2}$ \\ 'Department of Pathology, \\ The University of Chicago, Chicago, \\ IL, USA; ${ }^{2}$ QualTek Molecular \\ Laboratories, Newtown, PA, USA; \\ ${ }^{3}$ Corcept Therapeutics, Menlo Park, \\ CA, USA; ${ }^{4}$ Department of Psychiatry \\ and Behavioral Sciences, Stanford \\ University, Stanford, CA, USA
}

\begin{abstract}
Background: Glucocorticoid receptor (GR) activity has been associated with chemotherapy resistance and poor outcomes in patients with triple negative breast cancer (TNBC). The aim of this study was to develop an immunohistochemistry (IHC) assay to assess GR expression in archival formalin-fixed, paraffin-embedded human invasive breast carcinoma samples.
\end{abstract}

Methods: An optimized GR assay protocol was developed using rabbit monoclonal antibody to GR clone D8H2. Precision and reproducibility of the GR IHC assay was determined by conducting multiple staining runs of four invasive breast carcinoma samples using replicate serial sections. Assay sensitivity was examined in 50 TNBC samples $(>10 \mathrm{~mm})$ obtained from a tumor bank, and 43 paired TNBC samples from a tissue microarray (TMA) (1.5 mm). GR positivity was assessed using a percent scoring approach with a $\geq 10 \%$ cutoff for nuclear staining of tumor cells at any intensity. Analysis of the paired TMA cores was performed by averaging the scores of the two cores for each case.

Results: Equivalent cellular patterns of GR reactivity were observed in all replicates from the multiple staining runs; coefficients of variation did not exceed $4.7 \%$ for average $\mathrm{H}$-scores greater than 3.4 , thus meeting the criteria for assay precision and reproducibility (coefficient of variation $\leq 20 \%$ ). GR expression in TNBC single-tissue samples and TMA cores was characterized as mostly nuclear, with some concurrent cytoplasmic reactivity. Eighty-four percent of the 49 evaluable TNBC samples and $60 \%$ of the 42 evaluable paired TMA samples were positive for GR expression.

Conclusion: A robust and reproducible GR IHC assay was successfully developed for use in invasive breast carcinoma tissues. Differences in GR expression between larger single tissues and smaller TMA cores illustrate the heterogeneity of the disease, as well as potential intratumoral heterogeneity. This assay is currently being utilized in clinical trials of mifepristone, a GR antagonist, in patients with TNBC.

Keywords: glucocorticoid receptor, immunohistochemistry, triple negative breast cancer, mifepristone

\section{Introduction}

Activation of the glucocorticoid receptor (GR), a member of the ligand-dependent nuclear receptor superfamily, regulates a variety of essential biological functions, including immune response, glucose homeostasis, inflammatory response, metabolism, and cellular survival. ${ }^{1-4}$ The GR regulates these functions through the transactivation or transrepression of target genes, or through other nongenomic mechanisms. ${ }^{1-3,5}$ The effects of GR activation are tissue- and cell-specific. ${ }^{6-8}$ In solid tumor cell lines and xenografted in
Correspondence: Gabrielle M Baker Department of Pathology, The University of Chicago, 584I South Maryland Avenue, MC 610I, Room P-633, Chicago, IL 60637, USA

Tel + I 7738348068

Fax +l 7737024633

Email gabrielle.baker@uchospitals.edu 
vivo models including breast cancer, glucocorticoid-mediated activity has been shown to inhibit apoptosis and chemotherapy-induced apoptosis. . $^{3,69,10}$ While not yet fully elucidated, several target genes of GR activation, including serum and glucocorticoid-regulated kinase-1 $(S G K-1)$ and mitogenactivated protein kinase phosphatase-1 (MKPl), in addition to nuclear factor-kappa-B (NF-אB) activity, appear to play a role in glucocorticoid-mediated chemotherapy resistance., $3,6,10,11$

Triple negative breast cancer (TNBC), which lacks significant expression of estrogen receptor (ER), progesterone receptor (PR), and human epidermal growth factor receptor 2 (HER2), comprises $12 \%-24 \%$ of all patients with breast cancer. ${ }^{12-14}$ TNBC is characterized as a heterogeneous and frequently aggressive form of breast cancer that lacks available targeted therapies. ${ }^{12}$ Although some patients with TNBC respond well to initial cytotoxic chemotherapy, a substantial portion of patients $(78 \%)$ fail to achieve complete response. ${ }^{15}$ Overall, these patients have significantly worse 3 -year survival rates compared with patients who have other forms of breast cancer and residual disease (68\% vs $88 \%$, $P=0.0001) .{ }^{15}$ Ongoing molecular, genomic, and biological analyses have identified various subtypes within TNBC with the goal of uncovering potential biomarkers that could lead to more effective individualized therapy. ${ }^{16,17}$

Recent studies suggest that at least $62 \%$ of primary invasive breast cancers express GR. ${ }^{18,19}$ A meta-analysis of gene expression from 1,378 early-stage breast cancer patients found that GR expression was associated with significantly shorter relapse-free survival in patients whose tumors did not express ER, regardless of whether the patients were treated with adjuvant chemotherapy or not. ${ }^{20} \mathrm{~A}$ more recent analysis of tissue samples from 999 cases of primary invasive breast cancer found a similar association between GR status and median survival, with significantly lower median survival among those with ER-negative tumors, including triple negative tumors. ${ }^{18}$ Therefore, treatments that antagonize the GR may be beneficial in some patients with breast cancer.

Preliminary investigation found that the addition of mifepristone, a GR antagonist, significantly increased the cytotoxic effect of chemotherapy in both preclinical in vitro and in vivo models of GR-positive TNBC. ${ }^{21}$ A small Phase I trial in patients with advanced breast cancer noted substantial benefit with mifepristone plus albumin-bound (nab)-paclitaxel in a number of patients (mostly with TNBC), including those previously treated with taxanes. ${ }^{22}$ Notably, the responses were seen mostly in patients with GR-positive and ER-negative disease. As a result of these findings, additional studies of mifepristone chemotherapy combinations are underway in breast cancer. ${ }^{23}$
In order to carry out these trials, the development of a validated assay to detect GR expression will be needed to identify patients who are most likely to benefit from treatment.

The use of immunohistochemistry (IHC) assays to evaluate ER and PR status and the use of IHC and fluorescence in situ hybridization to evaluate HER2 status are well established in the clinical evaluation of newly diagnosed invasive breast carcinomas. ${ }^{24,25}$ Likewise, an IHC assay for detecting GR status that can readily be adopted into routine clinical practice would be a highly useful diagnostic tool. The aim of this study was to develop and validate an IHC assay to assess GR expression in formalin-fixed, paraffin-embedded (FFPE) breast cancer tissues for use in clinical trials involving patients with TNBC.

\section{Materials and methods Antibody specificity testing}

Three different GR antibody candidates were chosen for comparative analysis: rabbit monoclonal antibody (mAb) Anti-GR (D8H2; Cell Signaling Technology [\#3660S], Danvers, MA, USA), rabbit mAb Anti-GR (D6H2L; Cell Signaling Technology [\#12041]), and mouse mAb Anti-GR (BuGR2; Thermo Fisher Scientific, MA1-510, Waltham, MA, USA). All three antibodies were tested with a rigorous set of varying assay conditions, including different pretreatments, antibody concentrations, and detection reagents in order to determine the optimal conditions to enhance each antibody's performance. Upon determination of preliminary assays, staining patterns in test tissues were compared. Ethical approval for the use of human tissue samples in this study was not required, as the samples came from commercial tissue banks and did not contain any personal identifiers. The three antibodies demonstrated mostly equivalent staining patterns in the tissues tested (positivity within the same regions of cells). The D8H2 and D6H2L clones detected mostly nuclear isoforms of GR and were both highly sensitive to GR expression by stromal cells. The D8H2 clone was more sensitive overall than D6H2L and detected more GR-expressing cells. The BuGR2 clone detected cytoplasmic and nuclear isoforms of GR, although with a broader staining pattern that appeared to be less specific compared with the other clones. It also did not appear to recognize stromal GR antigens. Thus, D8H2 was chosen as the optimal clone for further assay development and validation.

The sensitivity and specificity of clone D8H2 as an IHC reagent was assessed by using FFPE samples, including invasive breast carcinoma, adjacent normal breast tissue, invasive colon adenocarcinoma, and mixed normal and tumor multitissue blocks (MTBs), also known as multitissue "sausage" 
blocks, ${ }^{26}$ revealing differential levels of GR expression (Figure 1). MTBs include larger pieces of tissue than those found on typical tissue microarray (TMA), but still permit the inclusion of several FFPE samples on a single slide. In general, GR is recognized in invasive breast carcinomas, normal breast tissue, stromal cells, and T-lymphocytes. ${ }^{19,27}$ Colorectal adenocarcinoma, which has been shown to lack GR expression, ${ }^{28}$ was used as a control to confirm specificity of the GR antibody. Eight different invasive colon adenocarcinoma samples were tested with two GR clones (D8H2 and D6H2L). Both clones produced equivalent results, with only one sample showing tumor positivity, which is consistent with published rates of GR expression.

\section{GR IHC assay optimization}

FFPE breast cancer samples within MTBs were used for final assay optimization. The D8H2 antibody concentration, antibody incubation time, antigen retrieval reagents and methods, and antibody detection system were all tested as part of the optimization process. The $\mathrm{D} 8 \mathrm{H} 2$ concentrations tested ranged from 1:500 to $1: 10,000$, and the antibody incubation times ranged from 1 hour to overnight (16 hours). Multiple antigen retrieval methods were tested, including heating in citratebased (acid $\mathrm{pH}$ or neutral $\mathrm{pH}$ ) or Tris and/or chelator-based (basic $\mathrm{pH}$ ) buffers, either alone or in combination with digestion by a weak protease (Proteinase-K). Progressive iterative steps were employed based on the results of prior staining runs to identify the conditions that demonstrated accurate cellular localization of GR, a broad dynamic range of GR expression, an appropriate signal-to-noise ratio, and acceptable performance in positive and negative tissue controls.
Other than the protein block and primary antibody diluent (both from QualTek Proprietary, Newtown, PA, USA), all reagents tested are commercially available. Rabbit IgG (Cell Signaling Technology [\#3900S]) was used at the same concentration as D8H2 to determine any nonspecific (ie, antibody constant region) staining inherent in the detection reagents or tissues or arising in tissues; rabbit IgG does not control for the unique GR antigen binding region of clone D8H2.

\section{Optimized GR (D8H2) IHC protocol}

FFPE tumor tissue sections of 4-5 $\mu \mathrm{m}$ thickness were cut onto positively charged slides (Fisher ProbeOn Plus ${ }^{\mathrm{TM}}$, Thermo Fisher Scientific), baked at $65^{\circ} \mathrm{C}$ (dry heat) for 1 hour less than 1 week before use, deparaffinized in four changes of $100 \%$ xylene, and rehydrated with a graded ethanol series $(100 \%, 70 \%, 30 \%)$ to distilled water.

Prepared slides were incubated for 20 minutes at $>98^{\circ} \mathrm{C}$ in Citra Plus Target Retrieval Solution (BioGenex [Cat \#: HK080-9K], Fremont, CA, USA), using a commercial steamer as the heat source (Black and Decker HS1000 model steamer; Black and Decker, Baltimore, MD, USA). After cooling for 5 minutes, automated staining was performed using a TechMate $^{\text {TM }} 500$ or 1000 automated IHC staining platform (Roche Diagnostics, Oro Valley, AZ, USA) and WorkMate ${ }^{\mathrm{TM}}$ software, version 3.96. This automated platform uses a capillary gap process ${ }^{29}$ for all reagent changes, including antibody incubation, detection steps up to and including counterstaining, and intervening washes. All procedures were carried out at room temperature $\left(25^{\circ} \mathrm{C}\right)$. Following a 15-minute incubation with a protein serum block (QualTek Proprietary), slides were incubated with the anti-GR antibody
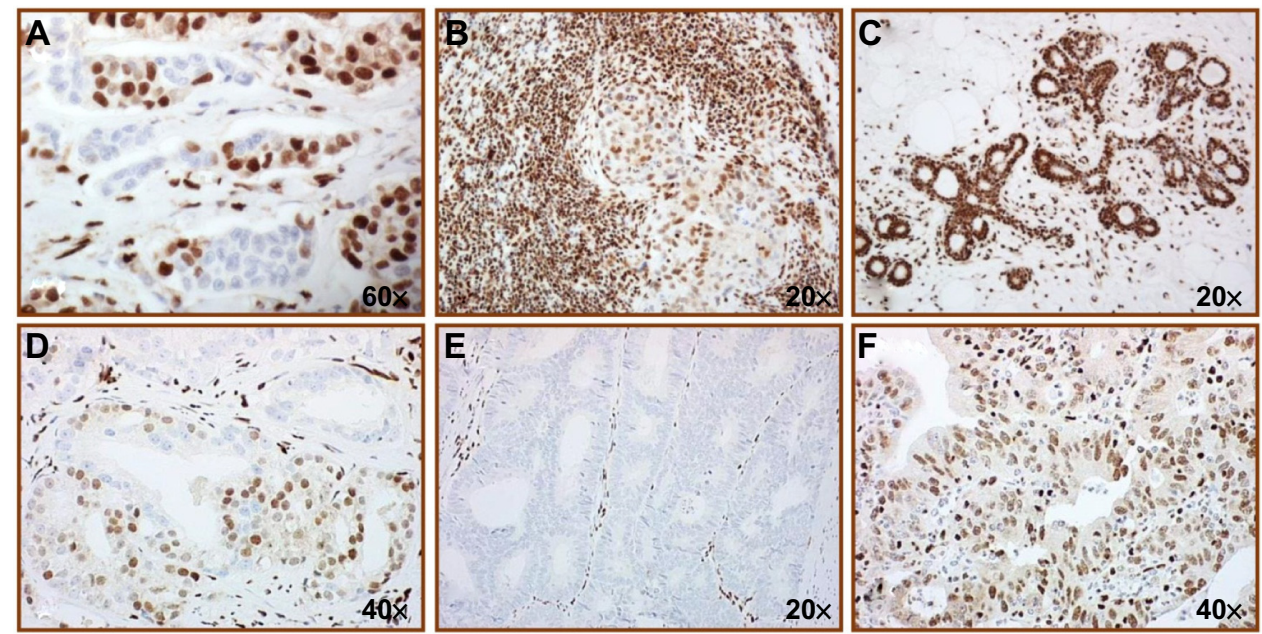

Figure I Nuclear and cytoplasmic staining of GR (D8H2) in invasive breast carcinoma (A); T-lymphocytes in TNBC (B); normal breast tissue (C); invasive prostate adenocarcinoma (D); and invasive colon adenocarcinoma (E and $\mathbf{F}$ ).

Abbreviations: GR, glucocorticoid receptor; TNBC, triple negative breast cancer. 
clone D8H2 (Cell Signaling Technology [\#3660S]) at a concentration of 1:1,750 in a primary antibody diluent (QualTek Proprietary) for 1 hour.

The Rabbit Polink2+ HRP (horseradish peroxidase) reagents kit (Golden Bridge International [GBI], Cat \#: D39110, Los Angeles, CA, USA), which is biotin-independent and reduces the potential for background or nonspecific staining from endogenous biotin, was used for primary antibody detection. The steps included were a 25-minute incubation with Rabbit Polink2+ secondary, a 7.5-minute peroxidase blocking step ( $3 \%$ USP $\mathrm{H}_{2} \mathrm{O}_{2}$, with $\sim 0.02 \%$ v/v Tween-20 added), a 25-minute incubation with Rabbit Polink2+ HRP conjugated polymer, and a 15-minute incubation with GBI (Cat \#: C09-100) 3,3'-diaminobenzidine (DAB) chromogen. Between all incubation steps, slides were extensively washed with tris-buffered saline containing $0.02 \% \mathrm{v} / \mathrm{v}$ Tween ${ }^{\circledR}-20$ detergent (TBST) (Thermo Fisher Scientific). The slides were counterstained with hematoxylin for 1 minute, rinsed in distilled water, dehydrated off platform in an ethanol series $(95 \%, 100 \%)$ and four changes of $100 \%$ xylene, and permanently sealed with coverslips (Cytoseal ${ }^{\mathrm{TM}}$ XYL mounting media, Thermo Fisher Scientific).

\section{Assessment of GR expression in tumor samples}

Assay validation was conducted in a Clinical Laboratory Investigation Amendment-accredited facility (QualTek Clinical Laboratories). The optimized GR IHC assay was used to evaluate GR expression patterns in archival FFPE tissue samples of TNBC $(n=50)$ obtained from a tumor bank, as well as TNBC samples within a TMA ( $n=43$; two cores each [1.5 mm]). Five control cases of invasive breast carcinoma with varying levels of ER, PR, and HER2 expression (Pantomics, Inc. [\#BRC964], Richmond, CA, USA), along with hematoxylin-and-eosin-stained and negative reagent control slides, were used as an aid to the GR scoring. All tissues samples were derived from treatment-naïve patients without any clinical outcome information.

A percent score was used to semiquantitatively assess tumor GR expression in samples with at least 100 viable invasive carcinoma cells. The intensity of nuclei staining was reported based on the $\mathrm{H}$-score method using 0 for negative staining, 1+ for weak staining, 2+ for moderate staining, and $3+$ for strong staining. ${ }^{30,31}$ For this assay, GR positivity was defined as $\geq 10 \%$ nuclear staining of tumor cells at any intensity. A board-certified pathologist scored nuclear tumor staining in the total area of viable tissue section available; areas of cytoplasmic or stromal staining, in situ carcinoma, necrosis, or obviously poorly fixed areas of tissue were not evaluated.

\section{Results}

\section{GR IHC assay precision and reproducibility}

Inter- and intra-assay variation of the GR IHC assay was assessed in a panel of four invasive breast carcinoma samples that comprehensively covered the expected range of GR expression in clinical samples. Within- and between-run precision were determined from multiple staining runs performed on different days by at least two different operators using different automated staining platforms. The tissues used in each run were replicate serial sections, with three sections per sample for GR expression and one section per sample as a negative control. All stained slides were reviewed by a board-certified pathologist using $\mathrm{H}$-scores, which range from 0 to 300 and consist of the total sum of $1 \times$ the percentage of cells with weak nuclear staining, $2 \times$ the percentage of cells with moderate nuclear staining, and $3 \times$ the percentage of cells with strong nuclear staining. ${ }^{31}$ Acceptance of the assay was based on the consistency in staining patterns and a coefficient of variation $(\mathrm{CV})$ among sample scores that does not exceed $20 \%$, although larger CVs observed at lower H-scores may be acceptable.

The samples reacted as expected, and equivalent cellular patterns of GR reactivity were observed in all replicates. Minor and graded changes in GR expression were noted in immunostaining abundance scores that could be attributed to increases or decreases in the amounts of tumor in each serial section. The $\mathrm{CV}$ for each sample set of GR intensity and abundance (H-score) did not exceed $4.7 \%$ for average H-scores greater than 3.4 (Table 1).

\section{IHC sensitivity in TNBC}

GR expression in TNBC single-tissue samples and TMA cores was characterized as mostly nuclear, but sometimes with concurrent cytoplasmic reactivity (Figure 2). Of the 50 single-tissue TNBC samples evaluated, one was excluded from analysis since it was not a carcinoma, four had no tumor staining, another four had minimal staining that did not meet the $10 \%$ cutoff criteria, and 41 had $10 \%$ or greater GR tumor staining (positivity rate of $84 \%$, Table 2 and Figure 3 ).

Analysis of the paired TMA cores was performed by averaging the scores of the two cores for each case. Of the 43 TNBC paired TMA cores, one pair could not be evaluated due to lack of tumor, 15 pairs had no tumor staining, two pairs had minimal staining that did not meet the $10 \%$ cutoff criteria, and 25 pairs had $10 \%$ or more GR tumor 
Table I GR intra- and inter-assay variability (precision and reproducibility) for TNBC samples

\begin{tabular}{|c|c|c|c|c|c|c|c|c|c|c|c|c|c|}
\hline \multirow[t]{2}{*}{ Sample } & \multicolumn{3}{|c|}{ Run I H-scores } & \multicolumn{3}{|c|}{ Run $2 \mathrm{H}$-scores } & \multicolumn{3}{|c|}{ Run 3 H-scores } & \multirow{2}{*}{$\begin{array}{l}\text { H-score } \\
\text { mean }\end{array}$} & \multirow{2}{*}{$\begin{array}{l}\text { H-score } \\
\text { SD }\end{array}$} & \multirow{2}{*}{$\begin{array}{l}\text { H-score } \\
\text { SEM }\end{array}$} & \multirow{2}{*}{$\begin{array}{l}\text { H-score } \\
\text { CV }\end{array}$} \\
\hline & Rep I & Rep 2 & Rep 3 & Rep I & Rep 2 & Rep 3 & Rep I & Rep 2 & $\operatorname{Rep} 3$ & & & & \\
\hline A & 200 & 200 & 210 & 210 & 210 & 210 & 210 & 230 & 210 & 210.0 & 8.7 & 2.9 & $4.1 \%$ \\
\hline B & 150 & 140 & 140 & 140 & 140 & 130 & 150 & 150 & 140 & 142.2 & 6.7 & 2.2 & $4.7 \%$ \\
\hline C & 3 & 5 & 3 & 3 & 3 & 3 & 3 & 3 & 5 & 3.4 & 0.9 & 0.3 & $25.6 \%$ \\
\hline D & 170 & 170 & 160 & 160 & 170 & 170 & 170 & 170 & 160 & 166.7 & 5.0 & 1.7 & $3.0 \%$ \\
\hline
\end{tabular}

Abbreviations: GR, glucocorticoid receptor; TNBC, triple negative breast cancer; SD, standard deviation; SEM, standard error of the mean; CV, coefficient of variation.

staining (positivity rate of $60 \%$, Table 2 and Figure 3). Further examination of the individual percent staining scores for each pair revealed that $34 \%$ (15/43) of the pairs had the same score, and $30 \%(13 / 43)$ of the pairs differed in scores by $30 \%$ or more (Table 3 ).

\section{Discussion}

Previous analysis has shown that GR expression in ERnegative breast cancer is associated with chemotherapy resistance. ${ }^{3}$ GR antagonism with mifepristone potentiates chemotherapy-induced apoptosis to varying degrees in TNBC cell lines. ${ }^{3,21}$ This variation may be related to the effects of GR antagonism on cell-survival pathways within specific TNBC subtypes. ${ }^{17,21}$ Results from a small randomized, Phase I trial of nab-paclitaxel plus mifepristone in nine patients, including eight patients with TNBC (4/8 initially diagnosed with ERpositive disease, but recurred with TNBC), were reported at the 2013 San Antonio Breast Cancer Symposium. ${ }^{22}$ Of note, four of the five patients who responded had previously relapsed after taxane-based treatment. Six patients had GRpositive disease, and of those, two had a complete clinical response and two had a partial response. All four patients with TNBC at initial diagnosis responded to therapy (three were GR-positive). Treatment was generally well tolerated with the exception of dose-limiting neutropenia resulting from elevated plasma levels of paclitaxel, which the authors felt was likely due to delayed clearance of nab-paclitaxel when coadministered with mifepristone. ${ }^{22}$ Identifying which
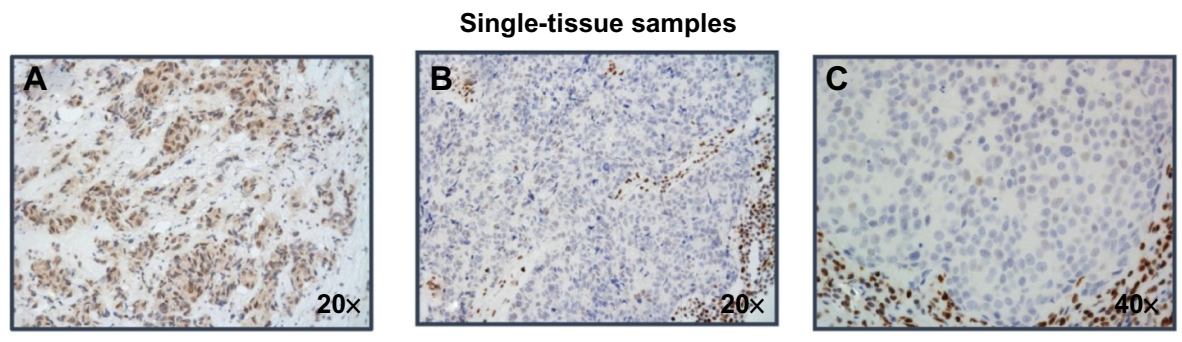

TMA samples
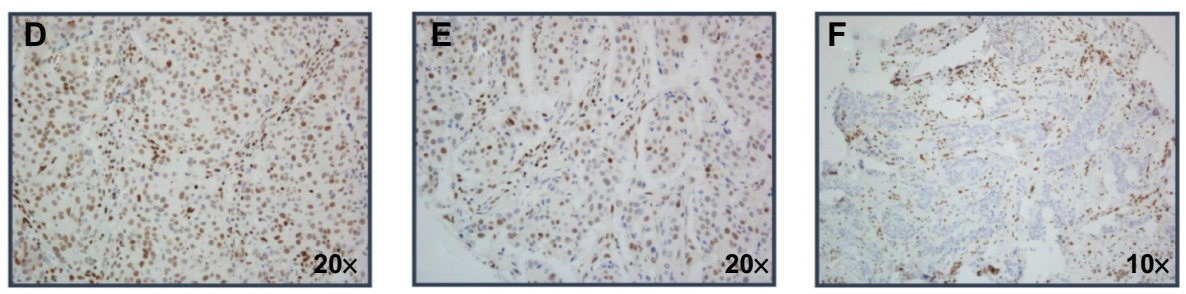

\begin{tabular}{|c|c|c|c|c|c|c|}
\hline \multirow{2}{*}{ Sample } & \multicolumn{2}{|c|}{ Staining intensity } & \multirow{2}{*}{$\begin{array}{c}\text { \% tumor } \\
\text { stain }\end{array}$} & $\begin{array}{c}\text { GR positivity } \\
(\mathbf{1 0} \% \text { cutoff })\end{array}$ & H-score \\
\cline { 2 - 4 } & $1+$ & $2+$ & $3+$ & 90 & Positive & 120 \\
A & 70 & 10 & 10 & 22 & Positive & 24 \\
B & 20 & 2 & 0 & 5 & Negative & 5 \\
C & 5 & 0 & 0 & 50 & Positive & 150 \\
D & 40 & 40 & 10 & 90 & Positive & 90 \\
E & 50 & 20 & 0 & 70 & Negative & 0 \\
F & 0 & 0 & 0 & 0 & \\
\hline
\end{tabular}

Figure 2 Examples of positive ( $\geq 10 \%$ ) and negative GR staining in TNBC single-tissue and TMA samples.

Notes: (A) Positive (90\%); (B) positive (22\%); (C) negative (5\%); (D) positive (90\%); (E) positive (70\%); (F) negative (0\%).

Abbreviations: GR, glucocorticoid receptor; TNBC, triple negative breast cancer; TMA, tissue microarray. 
Table 2 IHC staining thresholds by percent tumor staining and $\mathrm{H}$-scores for TNBC single-tissue and TMA samples, $\mathrm{n}$ (\%)

\begin{tabular}{|c|c|c|c|c|c|c|c|}
\hline & \multicolumn{7}{|c|}{$\%$ tumor stain thresholds } \\
\hline & 0 & $\mathrm{I}-9$ & $10-30$ & $31-50$ & $51-70$ & $71-90$ & $91-100$ \\
\hline Single tissue & $4(8)$ & $4(8)$ & $4(8)$ & $3(6)$ & $4(8)$ & $12(24)$ & $18(37)$ \\
\hline \multirow[t]{3}{*}{ TMA } & $15(36)$ & $2(5)$ & $6(14)$ & $8(19)$ & $3(7)$ & $4(10)$ & $4(10)$ \\
\hline & \multicolumn{7}{|c|}{$\mathrm{H}$-score thresholds } \\
\hline & 0 & $\mathrm{I}-9$ & $10-50$ & $51-100$ & $101-150$ & $151-200$ & $201-300$ \\
\hline Single tissue & $4(8)$ & $4(8)$ & $5(10)$ & $3(6)$ & $12(24)$ & II (22) & $10(20)$ \\
\hline TMA & $15(36)$ & $2(5)$ & $9(2 \mathrm{I})$ & $8(19)$ & $6(14)$ & I (2) & I (2) \\
\hline
\end{tabular}

Abbreviations: IHC, immunohistochemistry; TNBC, triple negative breast cancer; TMA, tissue microarray.

patients with TNBC will benefit from GR antagonism will be important to the design of future clinical trials.

Results from this IHC assay study found GR expression in $60 \%$ of TMA TNBC samples and $84 \%$ of single-tissue TNBC samples from treatment-naïve patients. The variation in GR expression likely reflects the heterogeneity present in TNBCs as a group, as well as intratumoral heterogeneity. Methodological differences in assay development (eg, antibody selection, tissue sampling, etc) make it difficult to compare results with previously reported analyses of GR expression in patients with breast cancer. ${ }^{18,19,32}$ For example,
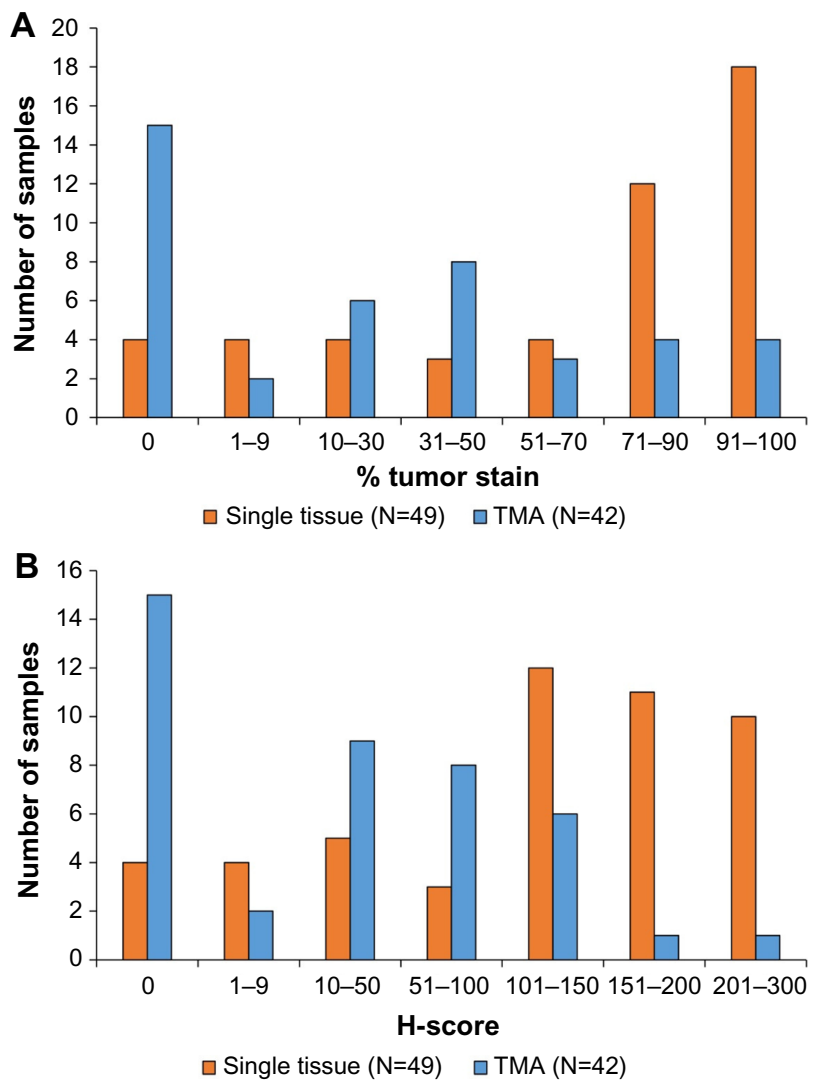

Figure $3 \mathrm{IHC}$ staining thresholds by percent tumor staining $(\mathbf{A})$ and $\mathrm{H}$-scores (B) for TNBC single-tissue and TMA samples.

Abbreviations: IHC, immunohistochemistry; TNBC, triple negative breast cancer; TMA, tissue microarray. earlier studies utilized TMA tissue samples, some of which included nonduplicated cores. ${ }^{19,32}$ Nonetheless, the $60 \%$ GR expression noted in TMA samples from this study is consistent with the recently reported $62 \%$ GR expression from a large analysis of TMA tissue samples of invasive breast carcinoma. ${ }^{18}$ The difference in penetrance between the larger single tissues $(>10 \mathrm{~mm})$ and smaller TMA cores $(1.5 \mathrm{~mm})$ from our analysis may provide useful information to help guide future GR testing procedures. Of note, $51 \%$ $(25 / 49)$ of the single tissues samples had $90 \%$ or greater tumor staining, compared with $14 \%$ of the TMA samples that had $90 \%$ or greater tumor staining. Therefore, larger tissue samples, including core needle biopsy or excision specimens, may be preferable for assessing GR expression and heterogeneity rather than the limited amount of tissue available for evaluation via TMA.

The development and use of a validated assay technique to detect GR expression is necessary to help reduce the potential for discordant test results, which could impact therapeutic decisions. An IHC assay to detect GR was selected based on the established diagnostic utility of IHC in routine breast cancer evaluation. Human colon adenocarcinoma tissue was used as an internal negative control in this study for GR specificity rather than null xenograft tumor sections and cell lines because of the similarities in processing the human FFPE colon adenocarcinoma tissues to that of the TNBC FFPE tissues. While xenografts and cell lines used to create xenografts can demonstrate conclusive assay specificity, they can sometimes

Table 3 TMA percent tumor stain comparison

\begin{tabular}{ll}
\hline & Number of core pairs \\
\hline Same score & 15 \\
$<30 \%$ difference & 11 \\
$30 \%-70 \%$ difference & 7 \\
$>70 \%$ difference & 6 \\
One or both cores unevaluable & 4 \\
Total core pairs & 43 \\
\hline
\end{tabular}

Abbreviation: TMA, tissue microarray. 
behave differently with IHC assays compared with human FFEP tumor tissues because of differences in composition, morphology, and format. Also, this assay was not optimized for cell lines, and cell lines were not readily available. Thorough precision testing demonstrated consistent and reproducible staining and established the robustness of the GR IHC assay. $A \geq 10 \%$ staining threshold was selected as the initial cutoff for GR positivity in order to minimize the exclusion of patients who may potentially benefit from GR antagonist therapy. However, this cutoff may be modified based on the outcomes of GR antagonist therapy in clinical populations. For instance, the historical cutoff for IHC ER positivity was originally based on earlier ligand-binding assays with corresponding IHC thresholds as high as $\geq 10 \%$, but in 2010 , the recommended threshold for ER and PR became $\geq 1 \%$ based on the clinical response and tolerability associated with endocrine therapies. ${ }^{25}$ Applying a higher cutoff threshold of $\geq 25 \%$ to the current analysis would result in minimal change in the percentage of GR-positive single-tissue samples (from $84 \%$ to $78 \%$ ), yet would reduce the percentage of GR-positive TMA samples from $60 \%$ to $48 \%$, further highlighting differences related to tissue sample size. Application of the GR assay in a clinical setting will help provide additional guidance on the most appropriate cutoff thresholds.

\section{Conclusion}

A robust and reproducible IHC assay protocol was developed for assessing GR expression in FFPE invasive breast carcinoma tissues. This assay is currently being utilized in clinical trials of the GR antagonist, mifepristone, in patients with TNBC, where it will provide additional information on the effects of GR antagonism on cytotoxic chemotherapy.

\section{Acknowledgments}

The authors thank Sarah Mizne, PharmD, of MedVal Scientific Information Services, LLC, for providing medical writing and editorial assistance. This study was sponsored by Corcept Therapeutics, Menlo Park, CA, USA. This manuscript was prepared according to the International Society for Medical Publication Professionals' "Good Publication Practice for Communicating Company-Sponsored Medical Research: the GPP3 Guidelines" and the International Committee of Medical Journal Editors' "Uniform Requirements for Manuscripts Submitted to Biomedical Journals.”

\section{Disclosure}

GMB is an employee of the University of Chicago. The University of Chicago has received research support, in the form of medicine and placebo tablets, from Corcept Therapeutics. Corcept also pays the University marketbased fees to perform limited laboratory services. TM is an employee of QualTek Molecular Laboratories, Newtown, PA, USA (contracted to perform assay study). TB and DN are employees of Corcept Therapeutics, Menlo Park, CA, USA. FJL is an employee of QualTek Molecular Laboratories, Newtown, PA, USA (contracted to perform assay study). The authors report no other conflicts of interest in this work.

\section{References}

1. Rhen T, Cidlowski JA. Antiinflammatory action of glucocorticoids - new mechanisms for old drugs. N Engl J Med. 2005;353(16):1711-1723.

2. Cole TJ, Blendy JA, Monaghan AP, et al. Targeted disruption of the glucocorticoid receptor gene blocks adrenergic chromaffin cell development and severely retards lung maturation. Genes Dev. 1995;9(13): $1608-1621$.

3. Wu W, Chaudhuri S, Brickley DR, Pang D, Karrison T, Conzen SD. Microarray analysis reveals glucocorticoid-regulated survival genes that are associated with inhibition of apoptosis in breast epithelial cells. Cancer Res. 2004;64(5):1757-1764.

4. Kadmiel M, Cidlowski JA. Glucocorticoid receptor signaling in health and disease. Trends Pharmacol Sci. 2013;34(9):518-530.

5. McKenna NJ, Xu J, Nawaz Z, Tsai SY, Tsai MJ, O’Malley BW. Nuclear receptor coactivators: multiple enzymes, multiple complexes, multiple functions. J Steroid Biochem Mol Biol. 1999;69(1-6):3-12.

6. Mikosz CA, Brickley DR, Sharkey MS, Moran TW, Conzen SD. Glucocorticoid receptor-mediated protection from apoptosis is associated with induction of the serine/threonine survival kinase gene, sgk-1. J Biol Chem. 2001;276(20):16649-16654.

7. Moran TJ, Gray S, Mikosz CA, Conzen SD. The glucocorticoid receptor mediates a survival signal in human mammary epithelial cells. Cancer Res. 2000;60(4):867-872.

8. Helmberg A, Auphan N, Caelles C, Karin M. Glucocorticoid-induced apoptosis of human leukemic cells is caused by the repressive function of the glucocorticoid receptor. EMBO J. 1995;14(3):452-460.

9. Zhang C, Wenger T, Mattern J, et al. Clinical and mechanistic aspects of glucocorticoid-induced chemotherapy resistance in the majority of solid tumors. Cancer Biol Ther. 2007;6(2):278-287.

10. Pang D, Kocherginsky M, Krausz T, Kim SY, Conzen SD. Dexamethasone decreases xenograft response to paclitaxel through inhibition of tumor cell apoptosis. Cancer Biol Ther. 2006;5(8):933-940.

11. Huang Y, Johnson KR, Norris JS, Fan W. Nuclear factor-kB/IkB signaling pathway may contribute to the mediation of paclitaxel-induced apoptosis in solid tumor cells. Cancer Res. 2000;60(16):4426-4432.

12. Foulkes WD, Smith IE, Reis-Filho JS. Triple-negative breast cancer. N Engl J Med. 2010;363(20):1938-1948.

13. Haffty BG, Yang Q, Reiss M, et al. Locoregional relapse and distant metastasis in conservatively managed triple negative early-stage breast cancer. J Clin Oncol. 2006;24(36):5652-5657.

14. Bauer KR, Brown M, Cress RD, Parise CA, Caggiano V. Descriptive analysis of estrogen receptor (ER)-negative, progesterone receptor (PR)-negative, and HER2-negative invasive breast cancer, the so-called triple-negative phenotype: a population-based study from the California cancer Registry. Cancer. 2007;109(9):1721-1728.

15. Liedtke C, Mazouni C, Hess KR, et al. Response to neoadjuvant therapy and long-term survival in patients with triple-negative breast cancer. J Clin Oncol. 2008;26(8):1275-1281.

16. Jezequel P, Loussouarn D, Guerin-Charbonnel C, et al. Gene-expression molecular subtyping of triple-negative breast cancer tumours: importance of immune response. Breast Cancer Res. 2015;17(1):43. 
17. Lehmann BD, Bauer JA, Chen X, et al. Identification of human triplenegative breast cancer subtypes and preclinical models for selection of targeted therapies. J Clin Invest. 2011;121(7):2750-2767.

18. Abduljabbar R, Negm OH, Lai CF, et al. Clinical and biological significance of glucocorticoid receptor (GR) expression in breast cancer. Breast Cancer Res Treat. 2015;150(2):335-346.

19. Buxant F, Engohan-Aloghe C, Noel JC. Estrogen receptor, progesterone receptor, and glucocorticoid receptor expression in normal breast tissue, breast in situ carcinoma, and invasive breast cancer. Appl Immunohistochem Mol Morphol. 2010;18(3):254-257.

20. Pan D, Kocherginsky M, Conzen SD. Activation of the glucocorticoid receptor is associated with poor prognosis in estrogen receptor-negative breast cancer. Cancer Res. 2011;71(20):6360-6370.

21. Skor MN, Wonder EL, Kocherginsky M, et al. Glucocorticoid receptor antagonism as a novel therapy for triple-negative breast cancer. Clin Cancer Res. 2013;19(22):6163-6172.

22. Nanda R, Chennamaneni P, Gibson J, et al. A randomized phase I trial of nanoparticle albumin bound paclitaxel (nab-paclitaxel, Abraxane ${ }^{\circledR}$ ) with or without mifepristone for advanced breast cancer. Presented at: San Antonio Breast Cancer Symposium, December 10-14; 2013, San Antonio, TX.

23. Clinicaltrials.gov. Mifepristone clinical trials. Available from: https:// clinicaltrials.gov/ct2/results?term=mifepristone+breast+cancer $\&$ Searc $\mathrm{h}=$ Search. Accessed June 8, 2015.

24. Wolff AC, Hammond ME, Hicks DG, et al. Recommendations for human epidermal growth factor receptor 2 testing in breast cancer: American Society of Clinical Oncology/College of American Pathologists clinical practice guideline update. J Clin Oncol. 2013;31(31):3997-4013.
25. Hammond ME, Hayes DF, Dowsett M, et al. American Society of Clinical Oncology/College of American Pathologists guideline recommendations for immunohistochemical testing of estrogen and progesterone receptors in breast cancer (unabridged version). Arch Pathol Lab Med. 2010;134(7):e48-e72.

26. Battifora H. The multitumor (sausage) tissue block: novel method for immunohistochemical antibody testing. Lab Invest. 1986;55(2): 244-248.

27. Lien HC, Lu YS, Cheng AL, et al. Differential expression of glucocorticoid receptor in human breast tissues and related neoplasms. J Pathol. 2006;209(3):317-327.

28. Lien HC, Lu YS, Shun CT, Yao YT, Chang WC, Cheng AL. Differential expression of glucocorticoid receptor in carcinomas of the human digestive system. Histopathology. 2008;52(3):314-324.

29. Reed JA, Manahan LJ, Park CS, Brigati DJ. Complete one-hour immunocytochemistry based on capillary action. Biotechniques. 1992;13(3): 434-443.

30. McCarty KS Jr, Miller LS, Cox EB, Konrath J, McCarty KS Sr. Estrogen receptor analyses. Correlation of biochemical and immunohistochemical methods using monoclonal antireceptor antibodies. Arch Pathol Lab Med. 1985;109(8):716-721.

31. Ishibashi H, Suzuki T, Suzuki S, et al. Sex steroid hormone receptors in human thymoma. J Clin Endocrinol Metab. 2003;88(5):2309-2317.

32. Belova L, Delgado B, Kocherginsky M, Melhem A, Olopade OI, Conzen SD. Glucocorticoid receptor expression in breast cancer associates with older patient age. Breast Cancer Res Treat. 2009;116(3): $441-447$.
Cancer Management and Research

\section{Publish your work in this journal}

Cancer Management and Research is an international, peer-reviewed open access journal focusing on cancer research and the optimal use of preventative and integrated treatment interventions to achieve improved outcomes, enhanced survival and quality of life for the cancer patient. The journal welcomes original research, clinical \& epidemiological

\section{Dovepress}

studies, reviews \& evaluations, guidelines, expert opinion \& commentary, case reports \& extended reports. The manuscript management system is completely online and includes a very quick and fair peerreview system, which is all easy to use. Visit http://www.dovepress.com/ testimonials.php to read real quotes from published authors 